\title{
Applying Value Stream Mapping to eliminate waste: a case study of an original equipment manufacturer for the automotive industry
}

\section{António Pedro Lacerda, Ana Raquel Xambre \& Helena Maria Alvelos}

To cite this article: António Pedro Lacerda, Ana Raquel Xambre \& Helena Maria Alvelos (2016) Applying Value Stream Mapping to eliminate waste: a case study of an original equipment manufacturer for the automotive industry, International Journal of Production Research, 54:6, 1708-1720, DOI: $10.1080 / 00207543.2015 .1055349$

To link to this article: http://dx.doi.org/10.1080/00207543.2015.1055349

Published online: 18 Jun 2015.

Submit your article to this journal $\sqsubset$

Џلll Article views: 821

View related articles $\sqsubset$

View Crossmark data ¿

Citing articles: 3 View citing articles $\sqsubset$ 


\title{
Applying Value Stream Mapping to eliminate waste: a case study of an original equipment manufacturer for the automotive industry
}

\author{
António Pedro Lacerda ${ }^{\mathrm{a}}$, Ana Raquel Xambre ${ }^{\mathrm{a}, \mathrm{b} *}$ and Helena Maria Alvelos ${ }^{\mathrm{a}, \mathrm{b}}$ \\ ${ }^{a}$ Department of Economics, Management and Industrial Engineering, University of Aveiro, Aveiro, Portugal; ${ }^{b}$ CIDMA - Center for \\ Research and Development in Mathematics and Applications, University of Aveiro, Aveiro, Portugal
}

(Received 15 September 2014; accepted 19 April 2015)

\begin{abstract}
Since its beginning, lean manufacturing has built a worldwide reputation based on results related to production improvement and cost reduction in several companies. This management philosophy focuses on customer value creation through the elimination of production wastes. Lean methods and techniques have spread their scope from the automotive industry to a wide range of industries and services. This article presents a case study that describes the use of the lean tool value stream mapping in the production process of automotive parts for a major automotive company. At the beginning of the project, relevant data from the process were collected and analysed. Subsequently, the initial process was mapped, the related wastes were identified, and then future processes were mapped and financial results were estimated. The proposals were presented on kaizen meetings, the action plan was discussed and the decision regarding which option to choose was taken. Consequently, the Cycle Time and the level of the workforce were reduced, the process was improved and savings were obtained.
\end{abstract}

Keywords: lean manufacturing; continuous improvement; value-stream mapping; automotive industry; plastic injection

\section{Introduction}

The economic crisis that Europe currently faces has had a huge impact on companies' revenue. In order to strive through this period, many were forced to implement cost-saving management philosophies; one among them is lean manufacturing. Lean manufacturing is based on the principles of the Toyota Production System (TPS). In essence, lean manufacturing philosophy focuses on customer value maximisation through the elimination of production wastes (Womack and Jones 2003; Belekoukias, Garza-Reyes, and Kumar 2014). Contrary to product standardisation and assembly lines, lean thinking promotes small production lots and quick changeovers thus reducing production time and focusing on product quality and diversity at a competitive price (Womack, Jones, and Roos 1990; Rahani and al-Ashraf 2012). This article describes the work that was carried out in a Portuguese original equipment manufacturing company, operating in the injection moulding industry, that supplies major automotive companies. A mid- to long-term strategic decision led the company to invest on a production project of plastic parts for a luxury car of a current customer. The work was carried out during a period of 8 months, and its main objective was to improve the performance of the production process, through the reduction of wastes and thus increasing its quality and efficiency.

In order to achieve the proposed objectives, firstly lean manufacturing and continuous improvement methods, mainly value stream mapping (VSM), were analysed and considered. Afterwards, production data related to the project, both from documentation and on-site, were collected and analysed. Subsequently, the following steps were followed: (i) the mapping of the current production process and the identification of critical points, (ii) the mapping of the desired production process together with the development of the action plan required to implement the proposed changes and (iii) the analysis of the financial impact of those changes.

This article is organised as follows: the current section makes an introduction to the project, its objectives and the methodology followed; the second section consists of a brief description of lean manufacturing and continuous improvement tools and metrics used in the project; the third section reports the analysis and implementation made during the project to achieve the proposed objectives; and finally, the fourth section describes the main conclusions of the work.

\footnotetext{
*Corresponding author. Email: raquelx@ua.pt 


\section{Lean manufacturing and continuous improvement}

By the end of the World War II, TPS was developed in the automotive industry by Toyota's executive Taiichi Ohno. Unlike Henry Ford's mass production, this system focused primarily on the quality and diversity of the products. Techniques such as just-in-time production, small lot sizes and quick changeover were used to reduce production costs. TPS became the basis of a management philosophy called lean manufacturing, whose primary objective is the maximisation of value for the customer through the elimination of production wastes (Krafcik 1988; Womack and Jones 2003). Value can be described as the ability to provide products or services at the right time and at the appropriate price in order to satisfy customer's needs. Therefore, it can only be defined by the customer and it should be the starting point of lean thinking (Womack, Jones, and Roos 1990; Womack and Jones 2005).

The specification of value is therefore considered the first of five lean principles. The second one is the identification of the value stream, which consists of all the specific actions required to develop and manufacture a product or deliver a service. The third principle is flow: once the value is defined, the value stream for a certain product mapped and wastes eliminated, products should flow between the remaining value-added steps. The next principle is pull, which means letting customers pull the product according to their needs rather than pushing unwanted products onto the customers. Finally, the fifth principle is perfection that tells us that there is no end to the process of reducing wastes while improving the product offered to the customer (Womack and Jones 2003; Hines, Holwe, and Rich 2004; Bhasin and Burcher 2006).

Muda, the Japanese word for waste, is related to every activity that does not add value to a product. It is both time and resource consuming, and so it makes the product more expensive (Chen, Ye, and Shady 2010). In an industrial environment, there are three kinds of activities: the one that adds value to the final product that naturally should be maintained, the non-value adding but unavoidable (type one muda) that should be analysed and, whenever possible, reduced and the non-value adding and avoidable (type two muda) that should be eliminated (Womack and Jones 2003).

As Ohno (1988) refers, the timeline between the costumer's order and the product's delivery should be studied and the related wastes should be eliminated in order to reduce its duration. The original seven common wastes in an industrial environment that were originally identified by Ohno (1988) are briefly described below.

- Defects - Quality problems that can often result in complaints from customers or be previously detected by inspection or maintenance teams. These problems are typically related to the lack of standard procedures and quality control systems, or to human failure, and have a negative impact on both production costs and productivity.

- Inventory - The surplus of inventory usually derives from the existence of production bottlenecks, slow changeovers or unbalanced processes. As a consequence, larger inventory holding areas and more handling operations are needed.

- Motion - Workers movement that does not add value to the product. This is often related to the placing of tools and components within the station or to ergonomic aspects that demand bigger efforts from the workers than it should.

- Over processing - Any operation or process that does not add value to the company can be considered a production waste and it can potentially increase the incidence of defects in the products.

- Overproduction - Production of more items than required by the customer. As a consequence, resources are used without financial return, stock and necessary warehouse space increase and production planning becomes less flexible.

- Transportation - Moving products and materials within a factory requires transportation systems that might be expensive, need maintenance, increase the Lead Time and sometimes damage parts.

- Waiting periods - Time wasted waiting for people, materials or equipment. It can happen due to flow obstructions, problems in stations' layout, delays in the delivery of components or lack of balanced production processes.

An additional waste has more recently been pointed out as important (Liker and Meier 2006) and, should therefore, be considered in the list.

- Talent - The waste of human potential can lead to missed improvement opportunities, considering that lean philosophy advocates that every individual is a thinker and can contribute with positive outcomes.

The large amount of success cases regarding the implementation of lean management methods in the automotive industry originated the adoption and adaptation of the philosophy and its use in organisations, from different industries and sectors, such as hotels, information technology companies, healthcare organisations, laboratories, forest products industries, public services, military organisations; also with positive results (Halwachs-Baumann 2010; Schiele and McCue 2011; Staats, Brunner, and Upton 2011; Simon and Canacari 2012; Teichgräber and de Bucourt 2012; Vlachos and Bogdanovic 2013; Bateman, Hines, and Davidson 2014; Lyon, Quesada-Pineda, and Crawford 2014). 
The implementation of lean manufacturing calls for constant development and refinement of its practices (Marodin and Saurin 2013). This led to the development of continuous improvement, a culture that simultaneously emerged in Japan, concerning the elimination of wastes and cost reduction (Imai 1997). Kaizen, as it is known, is a systematic approach that focuses on client needs. It is process orientated and encourages the participation and proactivity of every individual (Glover et al. 2011).

Implementing lean manufacturing is a complex process that encompasses all the hierarchy levels of an organisation and several aspects of the way the company works. Some authors have suggested ways to delineate the required steps for implementing lean (Black 2007; Serrano Lasa, Castro, and Laburu 2009; Vienazindiene and Ciarniene 2013) but there is still, according to Marodin and Saurin (2013), the need for further research so as to define coherent methods for implementing lean systems.

After a general description of the lean philosophy, the specific tools used in the case study are presented in the following subsections.

\subsection{Value Stream Mapping}

VSM is a powerful tool that enables the visualisation and understanding of the flow of material and information through the value chain. It is used to provide a global vision of the activities involved in the production process, and so, it enables the identification of wastes' sources. Lower production costs, faster response time to the customer and higher quality of products are therefore outputs that can be expected when applying VSM to a production process (Jones and Womack 2002; Pavnaskar, Gershenson, and Jambekar 2003; Rother and Shook 2003).

The participation of elements from key departments is required to obtain essential information about the production processes. After the mapping of the 'current state' using VSM symbols and identifying the process' wastes, the mapping of the desired 'future state' can be prepared along with the definition of an action plan to achieve it. There is a focus on the value represented by each activity, on process times and on financial aspects, all of which are determinant for the decision process (Jones and Womack 2002; Pavnaskar, Gershenson, and Jambekar 2003; Chen, Ye, and Shady 2010).

The lean metrics used in VSM will be presented in Section 2.3 of this article.

\subsection{Flow diagrams}

A flow diagram is a tool that is commonly used to study the movement of people and materials inside a factory. According to Meyers and Stewart (2002), it is usually drawn on plant layouts and it helps in identifying the following problems:

- Cross traffic - Points of intersection between paths that cause congestion and delays.

- Backtracking - Material moving backward, and not from the receiving to the shipping point of the plant.

- Distance travelled - Distance that materials and people have to travel in the plant. It should be kept as small as possible in order to save time, so machines and departments should be arranged accordingly.

- Procedure - If the layout is not suitable for the sequence of operations, it can originate backtracking and cross traffic. When the sequence cannot be changed, rearranging the location of the equipment should be considered.

The purpose of the use of flow diagrams was to find solutions for a more efficient work station, by shortening the distances travelled by people and materials.

\subsection{Lean metrics (KPI's)}

According to Rother and Shook (2003), lean metrics are very important when analysing the value stream and making decisions regarding a production system. The use of these metrics in VSM is essential to identify and eliminate nonvalue added activities.

Recent studies and relevant literature suggests the use of lean metrics like Lead Time, Value Added Time, Cycle Time and Takt Time when applying the VSM tool (Rother and Shook 2003; Seth and Gupta 2005; Abdulmalek and Rajgopal 2007; Duggan 2013; Surekha, Praveena Gowda, and Kulkarni 2013). Although in those works more sophisticated metrics are presented, the ones that are described and used, based on Rother and Shook (2003), were chosen because they are easy to understand and implement, and are consistent with the objectives and procedures of the company.

Lead Time is the time a product takes to flow through the value stream or the process, from start to finish (Rother and Shook 2003). 
Value Added Time refers to the time of the operations that, according to the client, add value to the product and for which he is willing to pay (Rother and Shook 2003).

Cycle Time is defined by the period of time between repetitions of the same task. It is, therefore, the time taken by all operations of the slowest station/operator of the process (Rother and Shook 2003).

Takt Time is the frequency in which a product must be produced, to meet the clients demand. This metric is used to synchronise the production and the sales cadence (Rother and Shook 2003). Takt Time can be determined using the following formula:

Takt Time $=\frac{\text { Available work time per shift }}{\text { Customer demand rate per shift }}$

\section{The case study}

The company where the case study was developed produces parts for the automotive industry. They produce 15 plastic parts for a specific client, used on the interior of a luxury car, and the case study focuses on one of those parts. In general, the main raw material used for producing those parts is ABS/PA (Acrylonitrile-Butadiene-Styrene and polyamide-based thermoplastic polymer blends), a material of high quality and performance. The manufacturing technologies used are thermoplastic injection, assembly of components and fabric bonding. The production process is described in the flowchart presented in Figure 1(a).

The company operates 10 months per year and has three main plant sections:

- Injection area - Consists of car parts moulding through thermoplastic injection and occasional components assembly' stations. It operates on three shifts of $8 \mathrm{~h}$ per day, from Monday to Friday, with injection machines with capacities varying from 150 to 900 tonnes force.

- Assembly area - Consists of components' assembly and fabric bonding stations. It normally operates on a single shift of $8 \mathrm{~h}$, of which $30 \mathrm{~min}$ are for lunch and $20 \mathrm{~min}$ for breaks, resting and stations' cleaning. When necessary, a second shift can be used with the same conditions.

- Stock warehouse - Consists of factory sections for both unfinished and final products deployment.
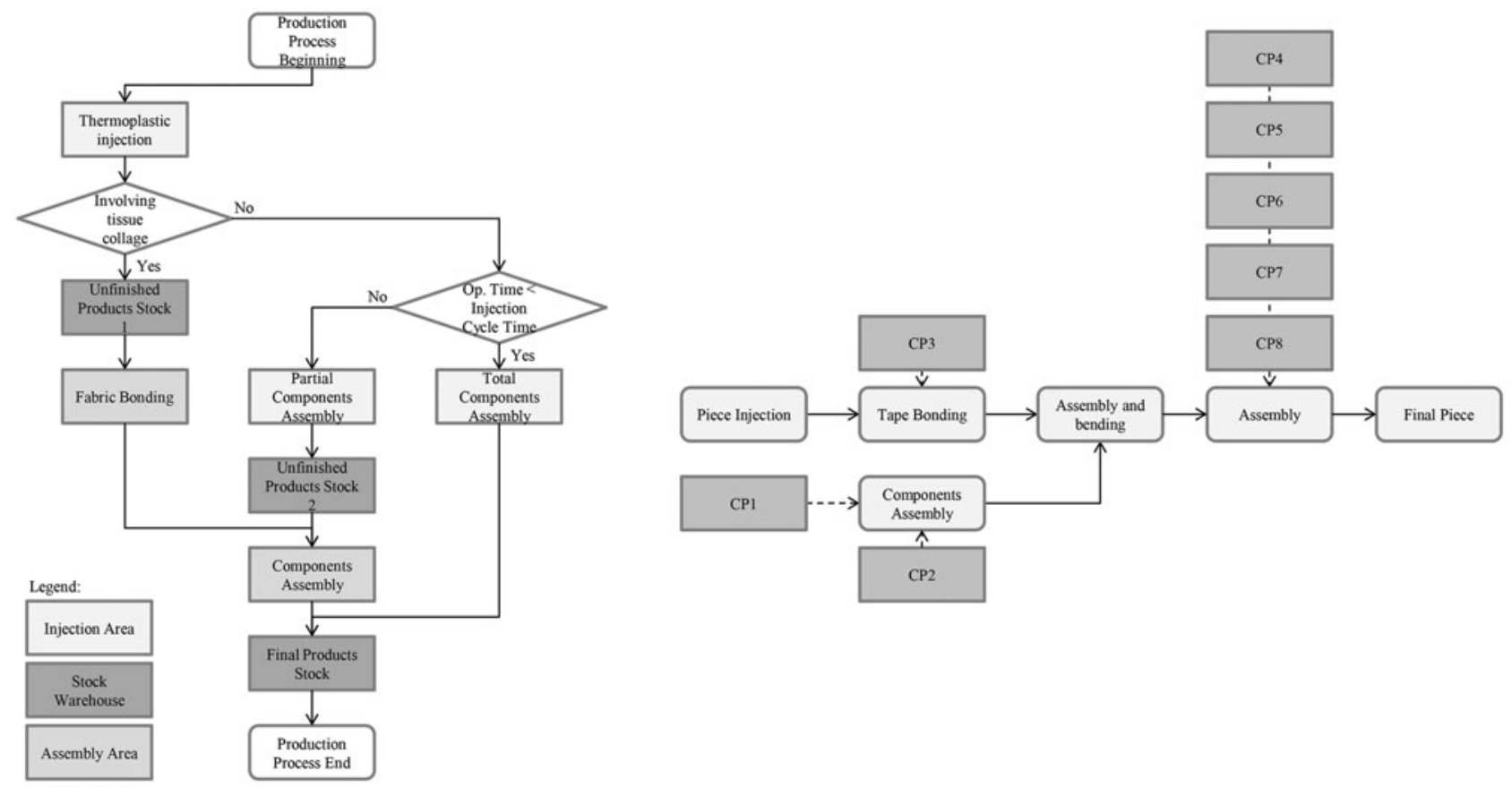

Figure 1. Production process: (a) general flowchart; (b) operations and components. 
This project was one of the first the company has had involving a luxury car. A production volume of parts for 16,688 cars per year have been defined between the company and the client. The client is responsible for providing data to the information system for orders' management, taking into account the semi-annual demand forecast and the weekly demand for products. The system manages the needs of raw materials and provides the necessary information to the plant sections. Inside the injection and the assembly area, the production orders are delivered to the stations, which are responsible for pulling the raw materials and components from the warehouse.

\subsection{Characterisation of the selected part}

The part analysed hereafter was selected due to the complexity of its production process and its manufacturing cost. Its production process is shown in Figure 1(b) and consists of thermoplastic injection followed by the activities related with the assembly of eight components (CP's).

\subsection{Data collection and analysis}

It is crucial to have data inputs in order to define the current state of any production process. Therefore, two types of data collection were performed. In order to understand all the activities of the process, the following documents were studied: Bill of Process, Packaging Range, Production Range and Pre-Series Assembly Process.

Simultaneously, a time study was performed using data collected by photo and video devices so as to determine the standard time of each task of the process.

Initial samples, with 15 observations each, were collected for all the tasks in order to estimate the values of the mean and of the standard deviation of their respective times. Also, the value of $10 \%$ was defined for the desired precision and the level of confidence chosen was of $95 \%$. It was then possible to determine the required sample size for determining the standard time of each task and, whenever the sample size was greater than 15 , additional observations of the activities had to be collected.

After gathering a valid number of observations, the observed time, the normal time and the standard time were calculated. The performance rating factor used to determine the normal time was of $80 \%$ since the production was in its initial phase and the operators had little experience on the tasks required. The value given to the allowance factor, used to define the standard time was $7 \%$, considering the standing position of the worker, the usual fatigue and the moderate monotony of the tasks under consideration.

The minimum time measuring unit defined by the company for the study was the second. Tables 1 and 2 present the obtained standard times for the activities, for each operator, through the injection and assembly stations. To facilitate the understanding of the activities carried out by the operators in the stations, the following code was used in their discrimination:

- $\mathrm{T}$ - Transportation of an object inside a station;

- A - Assembly activities;

- $\mathrm{R}$ - Rework operation used to correct defects;

- Q - Quality control operations, such as checking for spots or stains;

- U - Unpacking, unbagging, bagging and packing activities;

- B - Process of bending or cutting aluminium objects, sponges or tapes;

- I - Labelling of parts and packages.

Table 1. Process data of the injection station.

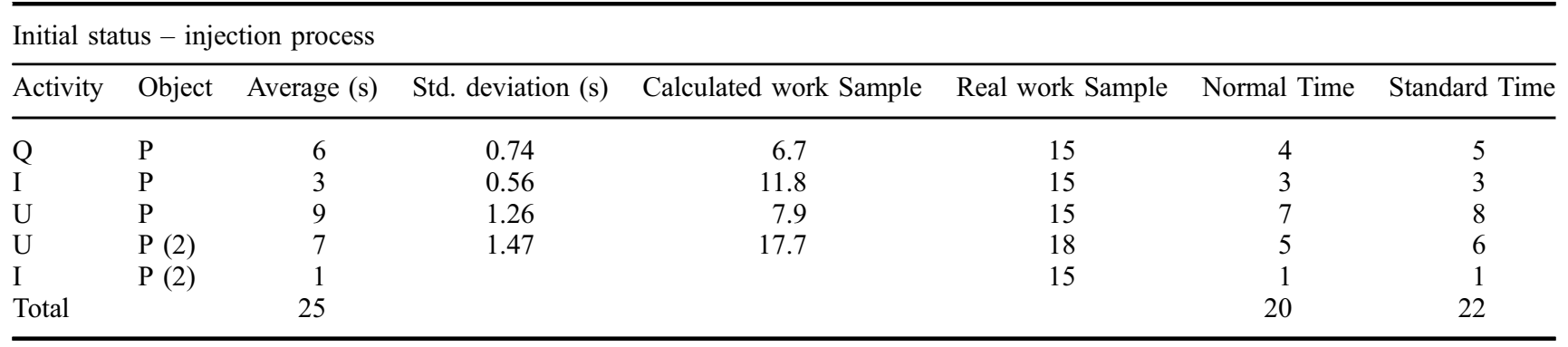


Table 2. Process data of the assembly station.

\begin{tabular}{|c|c|c|c|c|c|c|c|c|c|c|}
\hline \multicolumn{11}{|c|}{ Initial status - assembly process } \\
\hline \multirow[b]{2}{*}{ Activity } & \multirow[b]{2}{*}{ Object } & \multicolumn{3}{|c|}{ Operator } & \multirow{2}{*}{$\begin{array}{l}\text { Average } \\
\text { (s) }\end{array}$} & \multirow{2}{*}{$\begin{array}{l}\text { Std. Deviation } \\
\text { (s) }\end{array}$} & \multirow{2}{*}{$\begin{array}{c}\text { Calculated Work } \\
\text { Sample }\end{array}$} & \multirow{2}{*}{$\begin{array}{l}\text { Real Work } \\
\text { Sample }\end{array}$} & \multirow{2}{*}{$\begin{array}{l}\text { Normal } \\
\text { Time }\end{array}$} & \multirow{2}{*}{$\begin{array}{l}\text { Standard } \\
\text { Time }\end{array}$} \\
\hline & & 1 & 2 & 3 & & & & & & \\
\hline $\mathrm{T}$ & $\mathrm{P}$ & $\mathrm{X}$ & & & 2 & 0.35 & 13.7 & 15 & 1 & 2 \\
\hline $\mathrm{U}$ & $\mathrm{P}$ & $\mathrm{X}$ & & & 4 & 0.97 & 23.8 & 24 & 3 & 3 \\
\hline Q & $\mathrm{P}$ & $\mathrm{X}$ & & & 8 & 2.09 & 24.6 & 25 & 7 & 7 \\
\hline A & 4 & $\mathrm{X}$ & & & 31 & 5.94 & 13.8 & 15 & 25 & 27 \\
\hline A & 5 & $\mathrm{X}$ & & & 15 & 2.64 & 12.6 & 15 & 12 & 12 \\
\hline A & 6 & $\mathrm{X}$ & & & 16 & 2.16 & 7.3 & 15 & 13 & 13 \\
\hline $\mathrm{R}$ & 7 & $X$ & & & 9 & 1.85 & 15.5 & 17 & 7 & 8 \\
\hline A & 7 & $X$ & & & 2 & 0.46 & 15.7 & 16 & 2 & 2 \\
\hline A & 3 & $X$ & & & 81 & 7.83 & 3.6 & 15 & 65 & 69 \\
\hline A & $3(2)$ & $X$ & & & 23 & 4.38 & 14.5 & 16 & 18 & 19 \\
\hline $\mathrm{R}$ & $\mathrm{P}$ & $\mathrm{X}$ & & & 2 & 0.49 & 16.8 & 17 & 2 & 2 \\
\hline $\mathrm{T}$ & 1 & & $X$ & & 2 & 0.41 & 13.6 & 15 & 2 & 2 \\
\hline $\mathrm{U}$ & 1 & & $X$ & & 6 & 1.38 & 23.9 & 24 & 4 & 5 \\
\hline Q & 1 & & $X$ & & 23 & 5.15 & 19.6 & 20 & 18 & 20 \\
\hline A & 2 & & $\mathrm{X}$ & & 122 & 7.99 & 1.7 & 15 & 97 & 104 \\
\hline A & $2(2)$ & & $X$ & & 22 & 6.04 & 27.9 & 28 & 18 & 19 \\
\hline $\mathrm{R}$ & 1 & & $X$ & & 16 & 2.17 & 7.1 & 15 & 13 & 14 \\
\hline $\mathrm{R}$ & $1(2)$ & & $X$ & & 22 & 5.58 & 24.0 & 26 & 18 & 19 \\
\hline A & 1 & & $X$ & $X$ & 44 & 8.92 & 15.6 & 16 & 35 & 38 \\
\hline $\mathrm{R}$ & $1(3)$ & & & $X$ & 49 & 9.38 & 14.2 & 15 & 39 & 42 \\
\hline B & 1 & & & $X$ & 110 & 14.75 & 6.9 & 15 & 88 & 95 \\
\hline $\mathrm{R}$ & $1(4)$ & & & $X$ & 43 & 6.32 & 8.3 & 15 & 34 & 37 \\
\hline $\mathrm{R}$ & $1(5)$ & & & $X$ & 100 & 12.74 & 6.2 & 15 & 80 & 86 \\
\hline $\mathrm{R}$ & 8 & & & $\mathrm{X}$ & 15 & 1.11 & 2.2 & 15 & 12 & 13 \\
\hline A & 8 & & & $X$ & 24 & 3.07 & 6.2 & 15 & 19 & 21 \\
\hline I & $\mathrm{F}$ & & & $X$ & 12 & 2.03 & 10.3 & 15 & 10 & 11 \\
\hline $\mathrm{R}$ & $\mathrm{F}$ & & & $X$ & 17 & 3.59 & 17.7 & 18 & 13 & 14 \\
\hline $\mathrm{U}$ & $\mathrm{F}$ & & & $X$ & 8 & 1.72 & 18.7 & 19 & 6 & 7 \\
\hline $\mathrm{U}$ & $F(2)$ & & & $X$ & 6 & 0.65 & 4.6 & 15 & 5 & 5 \\
\hline I & $\mathrm{F}$ & & & $\mathrm{X}$ & 1 & & & 15 & 1 & 1 \\
\hline Total & & 165 & 220 & 368 & 836 & & & & 669 & 716 \\
\hline
\end{tabular}

As for the objects, the designations $\mathrm{P}$ and $\mathrm{F}$ refer to the plastic part that is injected and to the final product, respectively. The rest of the objects are the components used to assemble the final product. Component 1 is particularly important as it is a very sensitive aluminium part.

Concerning the activities identified by I.P(2) and by I.F, the methodology used to determine the standard time was different. Their duration was assumed to be $1 \mathrm{~s}$ due to the fact that, in both cases, the packages take 12 parts and it required less than $12 \mathrm{~s}$ to pack them all.

\subsection{Initial process state}

After collecting and analysing the data, the production process of the final part was analysed starting with the part moulding in the injection station, up to the packaging of the product in the final assembly station, going through the stock warehouse of unfinished products. In Figure 2, all the operations performed by each operator of the process are discriminated, as well as their duration and the lean metrics' values observed associated with the VSM. The code used to identify the operations in the VSM contains two characters: the first one refers to the type activity, and the second one refers to the object/component (as explained in Section 3.2).

Once again, it is important to point out that the analysis is only applied to the production process and not to all the flow of information and material of the value stream. The rectangle in Figure 2, surrounding the production stations, defines therefore the boundaries of the study.

The lean metrics (KPI's) used in the analysis of the process were chosen or adapted from the available literature (Duggan 2013; Surekha, Praveena Gowda, and Kulkarni 2013) and, when needed, defined within the company. Those KPI's are presented in Table 3 and are briefly described below. 


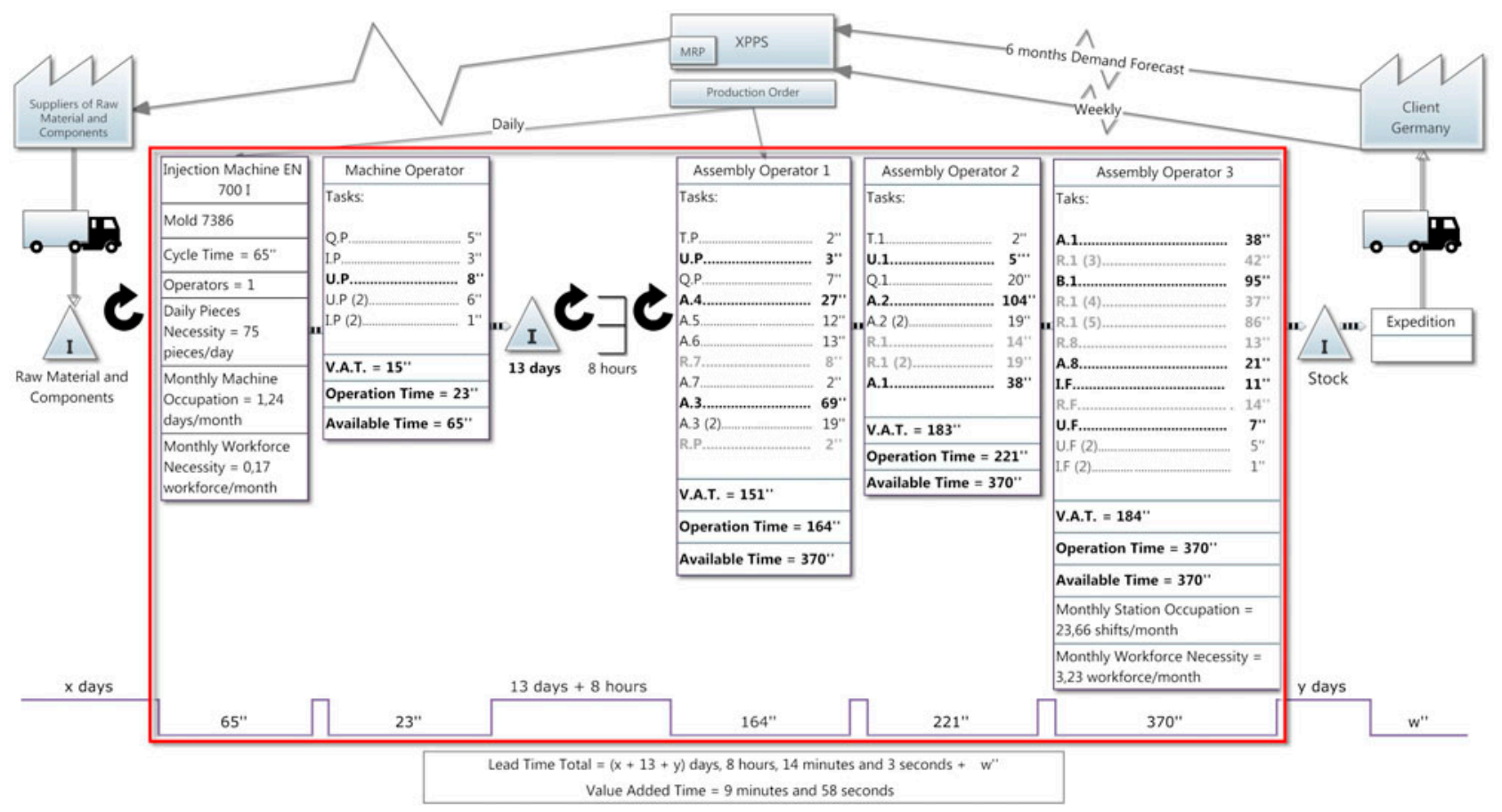

Figure 2. Map of the initial process state.

Table 3. Data from the initial state of the production process.

\begin{tabular}{lll}
\hline Lean metrics - initial state & Injection station & Assembly station \\
\hline Number of Operators & 1 & 3 \\
Cycle Time & $65 \mathrm{~s}$ & $370 \mathrm{~s}$ \\
Operation Time & $23 \mathrm{~s}$ & $717 \mathrm{~s}$ \\
Value Added Time & $15 \mathrm{~s}$ & $480 \mathrm{~s}$ \\
Monthly Occupation & 1.24 days/month & $23.66 \mathrm{shifts} / \mathrm{month}$ \\
Monthly Workforce Necessity & 0.17 workers/month & 3.23 workers $/$ month \\
\hline
\end{tabular}

The Monthly Occupation sets the need of production days per month, working at a specific Cycle Time, to meet the demand, and can be computed using the following formula:

$$
\text { Monthly Occupation }=\frac{\text { Daily parts necessity } \times \text { Cycle Time } \times \text { Days per month }}{\text { Daily seconds of work }}
$$

Regarding the Monthly Workforce Necessity, it is used to determine the workforce cost associated with a specific process and to ensure the best allocation of resources.

$$
\text { Monthly Workforce Necessity }=\frac{\text { Number of Operators } \times \text { Number of Shifts } \times \text { Monthly Occupation }}{\text { Days per month }}
$$

Table 3 presents the data collected and the metrics just described regarding the initial state of the process.

There is a particularity with operation A.1. Due to the sensibility of component 1, the given operation must be performed by operators 1 and 2 simultaneously. For this reason, although the operation time was considered for both operators, when determining the total operation time and the Value Added Time it was only added once.

The layout of the stations in the initial state is presented in the flow diagram of Figure 3. 

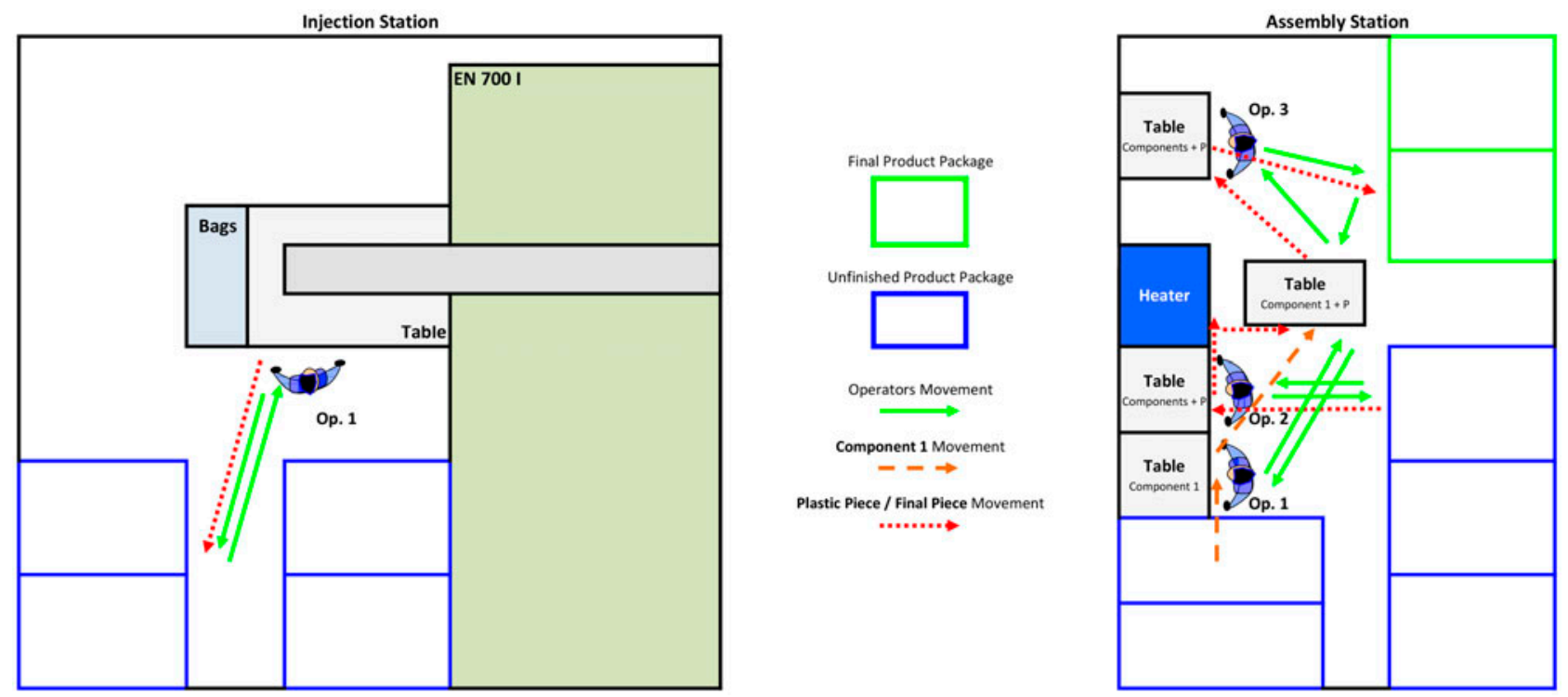

Figure 3. Stations' layout of the initial state of the production process.

The critical points represent either wastes of the production process or operations with improvement potential and are presented in Figure 2. Twelve operations, represented in bold black font, were identified as waste. Additionally, there are other five sources of waste, also highlighted in bold black font, that represent metrics that are considered critical, namely an inventory time of 13 days, and the differences between Value Added Time, operation time and available time for all of the four operators (machine operator, assembly operator 1, 2 and 3).

As for the reworks integrated in the production process in response to quality demands of the client are represented by the use of a bold grey font and account for nine critical points. These rework tasks are temporary until the necessary corrections (either to the part or to the production process) are made and consequently eliminate the need for those tasks.

A total of 26 critical points were identified, concerning two major groups.

The first group refers to the problems related to the process flow. For instance, the time consumed by the manual bending of aluminium engaging clips (operation B.1) represented one of the process major bottlenecks. Other critical points with potential for improvement are as follows: (i) the operator's traffic intersection (between operators 1 and 2), visible in Figure 3; (ii) the difference between the operation time, the available time and the Value Added Time for each operator and (iii) the inventory level.

The second group of critical points is related to quality issues. Spots in injected parts or stains and cracks in aluminium parts (component 1) were often identified when performing quality control operations and were considered, therefore, a major concern. Another problem was detected by the client, when some products were shipped without component 8 .

\subsection{Future process state}

After analysing the initial process state and considering the identified critical points, some solutions were presented in order to reduce waste and increase the quality and efficiency of the production process.

Although different solutions were studied, the selection of the final one was based on the best trade-off between the production performance and the ease of implementation.

The need of parts per day, the operating time of a shift in the assembly station and the minimum equipment efficiency defined by the company were essential to determine the Takt Time and the Planned Cycle Time. On the other hand, these metrics led to a Monthly Workforce Necessity of less than one operator in the assembly station, assuming a future total operation time of $261 \mathrm{~s}$ (as shown in Figure 4).

The Planned Cycle Time is a Takt Time considering a specific operational performance. It enforces a faster production rhythm to face unexpected problems and breaks that can endanger the service (Duggan 2013; Surekha, Praveena Gowda, and Kulkarni 2013). Therefore, the formula of the metric is as follows: 


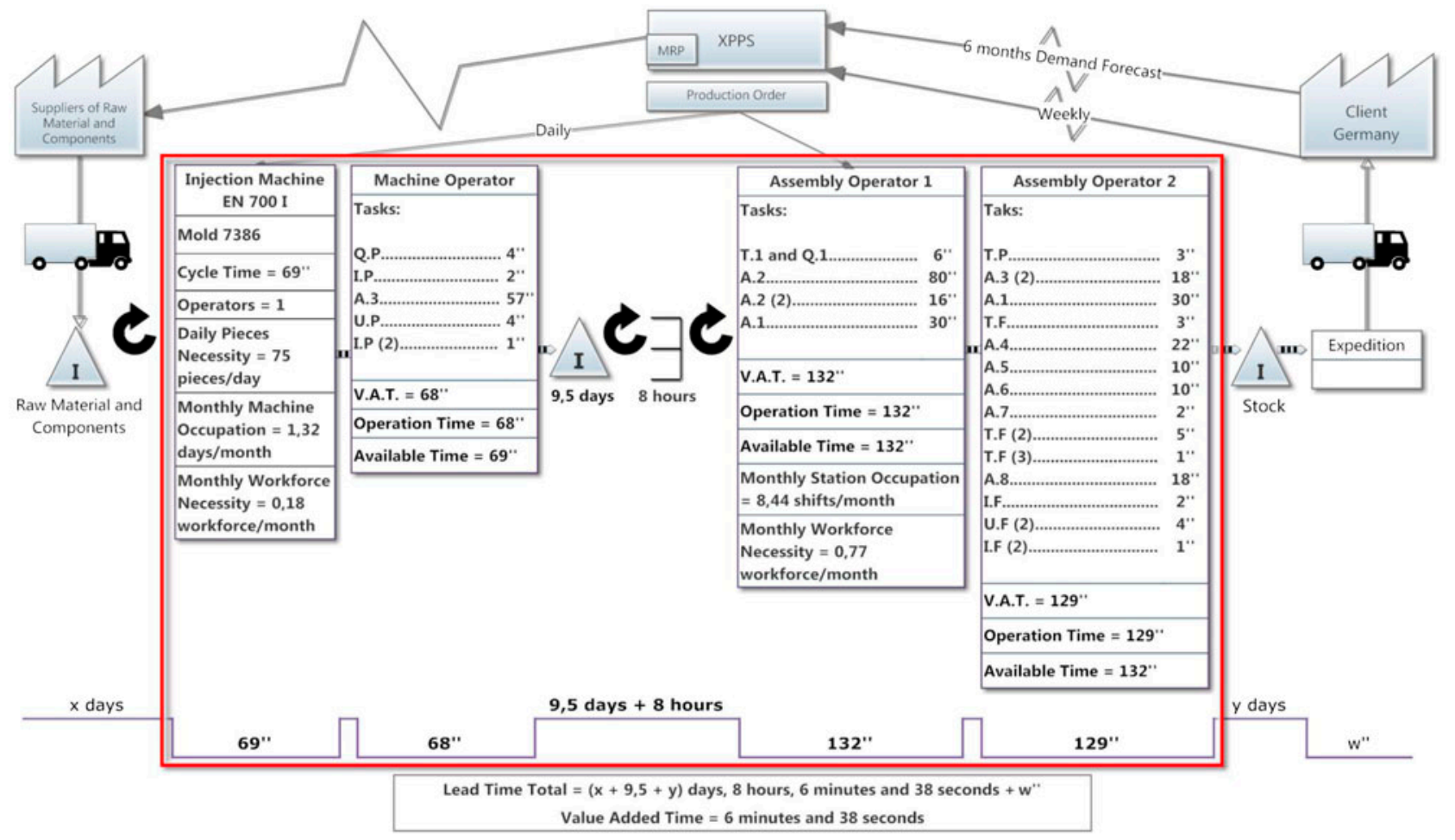

Figure 4. Map of the future process state.

Planned Cycle Time $=$ Takt Time $\times$ Operational Performance $(\%)$

In this case, the Monthly Workforce Necessity is determined by the following expression:

$$
\text { Monthly Workforce Necessity }=\frac{\text { OperationTime }}{\text { Planned Cycle Time }}
$$

The results of the metrics used for the future state of the production process were the following:

$$
\text { Takt Time }=\frac{25,800}{75}=344 \mathrm{~s}
$$

Planned Cycle Time $=344 \times 0.9=310 \mathrm{~s}$

Table 4. Future state estimated data for the production process.

\begin{tabular}{lll}
\hline Lean metrics - future state & Injection station & Assembly station \\
\hline Number of Operators & 1 & 2 \\
Cycle Time & $69 \mathrm{~s}$ & $132 \mathrm{~s}$ \\
Operation Time & $68 \mathrm{~s}$ & $231 \mathrm{~s}$ \\
Value Added Time & $68 \mathrm{~s}$ & $231 \mathrm{~s}$ \\
Monthly Occupation & 1.32 days/month & 8.44 shifts $/$ month \\
Monthly Workforce Necessity & 0.18 workers/month & 0.77 workers/month \\
\hline
\end{tabular}



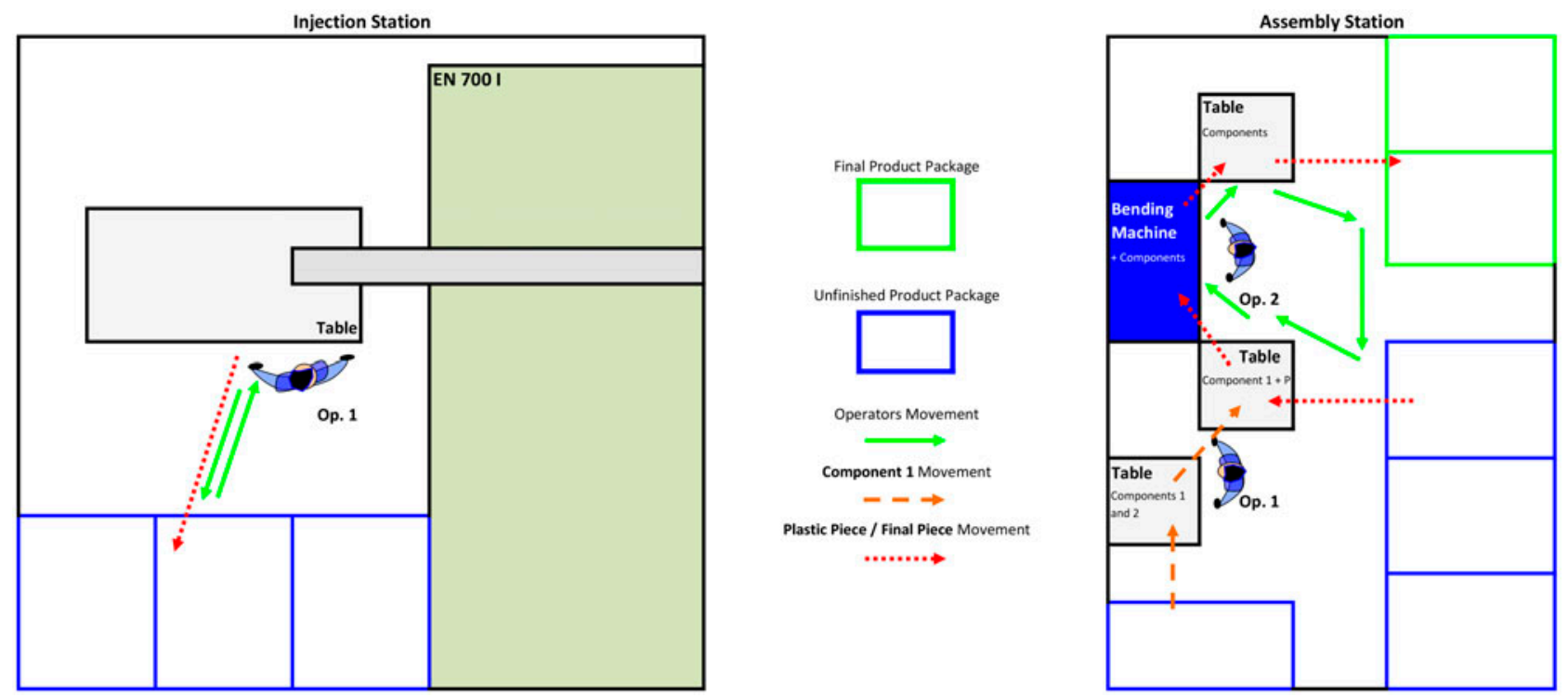

Figure 5. Stations' layout for the future state of the production process.

$$
\text { Monthly Workforce Necessity }=\frac{261}{310}=0.84 \text { workers } / \text { month }
$$

Despite the obtained value, the involvement of two operators is essential to perform the assembly of component 1 in the plastic part without putting at risk the quality of the product, as refereed in Section 3.3. Therefore, a mapping of a future state with two operators in the assembly station was developed, which enabled a decrease in the Monthly Occupation of that station.

In Figure 4, it is possible to observe the future process state balanced and without the critical points identified previously.

The estimated values for the lean metrics used in the study are presented in Table 4.

In Figure 5, the proposed layout for both stations, in the future state of the process, is presented.

To achieve the proposed future state of the process, an action plan was defined, containing 14 actions that gathered consensus among the main interveners in the project during kaizen events.

The critical points of the process were, therefore, solved through multiple approaches, depending on the type of problem.

Concerning the previously identified process flow problems, the bending of engaging clips (operation B.1) was improved through the acquisition of a bending machine, a solution financially supported by the client. This solution eliminated one of the major bottlenecks, turning a $95 \mathrm{~s}$ operation into a $1 \mathrm{~s}$ operation (operation T.F (3) - transport of the final part to the bending machine).

The traffic intersection between operators 1 and 2 was solved with the reformulation of the layout (Figure 5) and with the use of the $5 \mathrm{~S}$ methodology in the assembly station.

Mapping a balanced process (Figure 4) was the solution for the differences between the available time, the operation time and the Value Added Time.

In order to decrease the inventory level and achieve a more flexible process, the methodology Single Minute Exchange of Die (SMED) was applied to the exchange of the injection mould. As for the previously identified quality problems, changes in the injection parameters, in the structure of the plastic part and in the packages configuration, as well as the purchase of support structures, helped to eliminate spots, stains and cracks that occasionally occurred in the product.

To address the problem of shipping incomplete products, a Poka Yoke system was created with the use of optic sensors, alerting the operators whenever task A.8 had been skipped.

At that time, 11 of the 14 proposed actions were implemented and the Cycle Time of the assembly station was reduced by $62 \%$ (from 370 to $140 \mathrm{~s}$ ). The Cycle Time of $132 \mathrm{~s}$, estimated for the future state (see Table 4), corresponds to the expected value after the implantation of the final actions. 
Table 5. Savings and costs of the proposed solution.

\begin{tabular}{|c|c|c|}
\hline & Initial state & Future state \\
\hline & \multicolumn{2}{|c|}{ Savings } \\
\hline Monthly Workforce Necessity & 3.4 workers/month & 0.95 workers/month \\
\hline Monthly Occupation - Assembly Stations & $23.66 \mathrm{shifts} / \mathrm{month}$ & 8.44 shifts/month \\
\hline Unfinished Stock Warehouse Area & $24.33 \mathrm{~m}^{2}$ & $17.84 \mathrm{~m}^{2}$ \\
\hline Workforce savings $=\Delta^{\text {workforce }} \times 11.5(€ / \mathrm{h}) \times 8(\mathrm{~h}) \times 22($ days $) \times 10($ months $)$ & \multicolumn{2}{|c|}{$49,588 € /$ year } \\
\hline \multirow[t]{2}{*}{ Area savings $=\Delta^{\text {area }} \times 0.15\left(€ / \mathrm{m}^{2}\right) \times 24(\mathrm{~h}) \times 22$ (days) $\times 10$ (months) } & \multicolumn{2}{|c|}{$5,140.1 € /$ year } \\
\hline & \multicolumn{2}{|c|}{ Costs } \\
\hline Monthly Occupation - Injection Station & 1.24 days/month & 1.32 days/month \\
\hline Injection Machine Occupation Cost $=\Delta^{\text {occupation }} \times 48(€) \times 0$ (months) & \multicolumn{2}{|c|}{$921.6 € /$ year } \\
\hline Necessary Investment - Action Plan & \multicolumn{2}{|c|}{$3.500 €$} \\
\hline
\end{tabular}

Other important results were the reduction of the required number of operators, from four to three, and the reduction in $25 \%$ of the inventory level of the unfinished product, consequence of the referred SMED action. Decreasing the changeover time made it possible to have a smaller economic lot size, while maintaining the injection machine operational performance' level at $90 \%$.

The implementation of the solutions of the action plan was thus essential to reach the desired state of the process.

\subsection{Financial analysis}

A financial analysis was drawn measuring the costs and savings of the proposal presented in the previous section.

Due to privacy issues, the cost of workforce per hour, the price per square metre of the factory, the cost per hour of an injection machine operating and the action plan investment presented in the study are fictitious values. Nevertheless, they are proportional to the original values, so ratio calculations can be interpreted as real values (Table 5).

Finally, the difference between savings and costs was estimated in order to achieve the expected profit per year. It is important to point out that the cost of the investment is only used to estimate the profit for the first year so, in the first year, the costs only represent $8.1 \%$ of the savings, while, in the following years that proportion drops to $1.7 \%$.

Although the presented values did not correspond to the real values, it is important to emphasise that the profit obtained in the real situation was above what the company's responsible personnel anticipated.

\section{Conclusions}

Lean manufacturing methodologies have been implemented by the companies who intend to achieve competitive advantage and business sustainability (Pavnaskar, Gershenson, and Jambekar 2003).

The implementation of the lean tool VSM in the company studied aimed at reducing waste and thus increasing both the quality and efficiency of a production process. The production process of the part considered in this case study was firstly studied through data collection and analysis. The resulting information led to the definition of the initial state as well as to the identification of the critical points. Afterwards, a future state was mapped representing a balanced production process with a considerable waste reduction. A financial analysis was also performed, pointing out the expected profit of the proposed changes.

Lean wastes have been identified and fourteen solutions were proposed to eliminate them, of which eleven were implemented. As a result, the Cycle Time on the assembly sub-process was reduced from 370 to $140 \mathrm{~s}$, the number of operators was reduced from four to three, and the inventory level of the unfinished product has also decreased by $25 \%$, and one of the major bottlenecks was eliminated by changing a $95 \mathrm{~s}$ operation into a $1 \mathrm{~s}$ one. The financial analysis was essential for the decision-making process and provided better results than expected by the decision-makers. Ultimately, by implementing the action plan, the resulting production system became more functional and effective.

Apart from the improvements mentioned above, a change of mindset was also noticed within the operators involved in the production of the analysed part. By being frequently heard on-site and participating in kaizen events, they felt as an active part of the solution and so they became more committed in their work. The involvement of the workers and the change in terms of mentality were essential to implement new ways of working but also to keep the continuous improvement process on track (Hines, Holwe, and Rich 2004; Mann 2010; Vienazindiene and Ciarniene 2013). 
The results achieved in the case study suggest that the remaining solutions from the action plan could lead the production process to the proposed state and should therefore be implemented. The referred lean metrics should also continue to be closely monitored and the VSM tool should be applied to the complete value chain as well as to other processes in the company.

The implementation of the VSM described in this article was crucial for the reduction of waste and the increase of productivity of the process studied, thus providing evidence of the potential of this lean tool.

This article can be valuable both for researchers on the impact of lean thinking in manufacturing, as for companies' decision-makers or staff that want to implement lean tools, particularly VSM.

\section{Disclosure statement}

The authors state that they have no interests, financial or otherwise, which might be perceived as posing a conflict or bias.

\section{Funding}

This work was supported by Portuguese funds through the CIDMA - Center for Research and Development in Mathematics and Applications, and the Portuguese Foundation for Science and Technology ('FCT-Fundação para a Ciência e a Tecnologia'), within project UID/MAT/04106/2013.

\section{References}

Abdulmalek, Fawaz Z., and Jayant Rajgopal. 2007. "Analyzing the Benefits of Lean Manufacturing and Value Stream Mapping via Simulation: A Process Sector Case Study.” International Journal of Production Economics 107 (1): 223-236. doi:10.1016/ j.ijpe.2006.09.009.

Bateman, Nicola, Peter Hines, and Peter Davidson. 2014. "Wider Applications for Lean." International Journal of Productivity and Performance Management 63 (5): 550-568. doi:10.1108/IJPPM-04-2013-0067.

Belekoukias, Ioannis, Jose Garza-Reyes, and Vikas Kumar. 2014. "The Impact of Lean Methods and Tools on the Operational Performance of Manufacturing Organisations.” International Journal of Production Research 52 (18): 5346-5366. doi:10.1080/ 00207543.2014 .903348$.

Bhasin, S., and P. Burcher. 2006. "Lean Viewed as a Philosophy.” Journal of Manufacturing Technology Management 17 (1): 56-72. doi:10.1108/17410380610639506.

Black, J. T. 2007. "Design Rules for Implementing the Toyota Production System.” International Journal of Production Research 45 (16): 3639-3664. doi:10.1080/00207540701223469.

Chen, Joseph C., Ye Li, and Brett D. Shady. 2010. "From Value Stream Mapping toward a Lean/Sigma Continuous Improvement Process: An Industrial Case Study.” International Journal of Production Research 48 (4): 1069-1086. doi: 10.1080/ 00207540802484911.

Duggan, Kevin J. 2013. Creating Mixed Model Value Streams: Practical Lean Techniques for Building to Demand. Boca Raton, FL: CRC Press (Taylor \& Francis Group).

Glover, Wiljeana, Jennifer Farris, Elieen Van Aken, and Toni Doolen. 2011. "Critical Success Factors for the Sustainability of Kaizen Event Human Resource Outcomes: An Empirical Study.” International Journal of Production Economics 132 (2): $197-213$. doi:10.1016/j.ijpe.2011.04.005.

Halwachs-Baumann, Gabriele. 2010. “Concepts for Lean Laboratory Organization.” Journal of Medical Biochemistry 29 (4): $330-338$. doi:10.2478/v10011-010-0036-5.

Hines, Peter, Matthias Holwe, and Nick Rich. 2004. "Learning to Evolve: A Review of Contemporary Lean Thinking." International Journal of Operations \& Production Management 24 (10): 994-1011. doi:10.1108/01443570410558049.

Imai, Masaaki. 1997. Gemba Kaizen: A Commonsense, Low-cost Approach to Management. New York: McGraw-Hill.

Jones, Daniel T., and James P. Womack. 2002. Seeing the Whole. Mapping the Extended Value Stream. 1st ed. Brookline, MA: The Lean Enterprise Institute.

Krafcik, John. 1988. "Triumph of the Lean Production System.” Sloan Management Review 30 (1): 41-52.

Liker, Jeffrey K., and David Meier. 2006. The Toyota Way Fieldbook. New York: McGraw-Hill.

Lyon, S. W., H. J. Quesada-Pineda, and S. D. Crawford. 2014. "Reducing Electrical Consumption in the Forest Products Industry Using Lean Thinking." BioResources 9 (1): 1373-1386.

Mann, David. 2010. Creating a Lean Culture. New York: Productivity Press (Taylor \& Francis Group).

Marodin, Giuliano A., and Tarcisio A. Saurin. 2013. "Implementing Lean Production Systems: Research Areas and Opportunities for Future Studies.” International Journal of Production Research 51 (22): 6663-6680. doi:10.1080/00207543.2013.826831.

Meyers, Fred E., and James R. Stewart. 2002. Motion and Time Study for Lean Manufacturing. 3rd ed. Upper Saddle River, NJ: Prentice-Hall. 
Ohno, Taiichi. 1988. The Toyota Production System: Beyond Large-scale Production. Portland, OR: Productivity Press.

Pavnaskar, S. J., J. K. Gershenson, and A. B. Jambekar. 2003. "Classification Scheme for Lean Manufacturing Tools." International Journal of Production Research 41 (13): 3075 3090. doi: 10.1080/0020754021000049817.

Rahani, A. R., and Muhammad al-Ashraf. 2012. "Production Flow Analysis through Value Stream Mapping: A Lean Manufacturing Process Case Study." International Symposium on Robotics and Intelligence Sensors 41: 1727-1734. doi:10.1016/j.proeng.2012.07.375.

Rother, Mike, and John Shook. 2003. Learning to See: Value-stream Mapping to Create Value and Eliminate Muda. Brookline, MA: The Lean Enterprise Institute.

Schiele, Joseph J., and Clifford P. McCue. 2011. "Lean Thinking and Its Implications for Public Procurement: Moving Forward with Assessment and Implementation." Journal of Public Procurement 11 (2): 206-239.

Serrano Lasa, I., R. D. Castro, and C. O. Laburu. 2009. "Extent of the Use of Lean Concepts Proposed for a Value Stream Mapping Application." Production Planning and Control 20 (1): 82-98. doi:10.1080/09537280802685322.

Seth, Dinesh, and Vaibhav Gupta. 2005. "Application of Value Stream Mapping for Lean Operations and Cycle Time Reduction: An Indian Case Study.” Production Planning \& Control 16 (1): 44-59. doi:10.1080/09537280512331325281.

Simon, Ross W., and Elena G. Canacari. 2012. "A Practical Guide to Applying Lean Tools and Management Principles to Health Care Improvement Projects.” AORN Journal 95 (1): 85-103.

Staats, Bradley R., David James Brunner, and David M. Upton. 2011. "Lean Principles, Learning, and Knowledge Work: Evidence from a Software Services Provider." Journal of Operations Management 29 (5): 376-390. doi:10.1016/j.jom.2010.11.005.

Surekha, S., R. V. Praveena Gowda, and Manoj Kulkarni. 2013. "Standardized Work: An Important Principle Implemented in the Manufacturing Industry." International Journal of Management Research and Business Strategy 2 (2): 62-66.

Teichgräber, Ulf K., and Maximilian de Bucourt. 2012. "Applying Value Stream Mapping Techniques to Eliminate Non-value-added Waste for the Procurement of Endovascular Stents." European Journal of Radiology 81 (1): e47-e52. doi:10.1016/ j.ejrad.2010.12.054.

Vienazindiene, Milita, and Ramune Ciarniene. 2013. "Lean Manufacturing Implementation and Progress Measurement." Economics \& Management 18 (2): 366-373. doi:10.5755/j01.em.18.2.4732.

Vlachos, Ilias, and Aleksandra Bogdanovic. 2013. "Lean Thinking in the European Hotel Industry.” Tourism Management 36: $354-363$. doi:10.1016/j.tourman.2012.10.007.

Womack, James, and Daniel T. Jones. 2003. Lean Thinking: Banish Waste and Create Wealth in Your Corporation. New York: Free Press.

Womack, James, and Daniel T. Jones. 2005. "Lean Consumption.” Harvard Business Review 83 (3): 58-69.

Womack, James P., Daniel T. Jones, and Daniel Roos. 1990. The Machine That Changed the World. New York: Rawson. 